\title{
A genetic tool to manipulate litter size
}

\author{
Manuela Ferrari*, Anna K Lindholm and Barbara König
}

\begin{abstract}
Introduction: Experimental litter size manipulations are often not problem free. Typically conducted shortly after birth or oviposition, they do not account for the energy already invested into the production of the offspring. Such effects make it difficult to interpret the results from experimental litter size manipulations and therefore to study optimality of litter or clutch size, a long debated topic in evolutionary biology.
\end{abstract}

Results: We propose the use of a mating design based on a selfish genetic element, the $t$ haplotype, to reduce litter size in an eutherian mammal, the house mouse. Most $t$ haplotypes are recessive lethal and therefore lead to the death of all homozygous embryos. Litter sizes can be reduced by up to $50 \%$ by pairing a $+/ t$ female with $a+/ t$ male instead of a $+/+$ male.

Conclusions: This method allows litter size manipulation before birth without the use of invasive techniques, therefore providing an excellent tool for studying optimal litter size and ultimately helping to understand life history strategies.

Keywords: Litter size manipulation, House mouse, t haplotype, Optimal litter size

\section{Introduction}

Reproduction is a key feature of life and ultimately determines the success of an individual. At any point in time an animal should therefore optimise its reproductive effort to maximise lifetime reproductive success. Several tradeoffs play an important role in this process and determine to a large extent the life history of an animal. Pianka [1] described the most important trade-offs with three simple, but crucial questions: when should an individual reproduce, how much should it invest into the current reproductive event and how much into one single offspring? The number of offspring produced by birds and mammals per reproductive event has been widely investigated over the last decades. Optimal litter or clutch size nevertheless remains puzzling as it is likely to be determined by the current environment, the trade-off between current and future reproductive efforts, as well as by the trade-off between the number and the quality of the offspring [2].

\section{Testing optimality of litter or clutch size}

Already in the first half of the 20th century theories were developed to explain the huge variation observed in clutch

\footnotetext{
${ }^{*}$ Correspondence: manuela.ferrari@ieu.uzh.ch

Institute of Evolutionary Biology and Environmental Studies, University of

Zurich, Winterthurerstrasse 190, 8057 Zurich, Switzerland
}

size in birds. Lack [3] proposed that survival probability decreases with increasing clutch or litter size, because the amount of food parents can provision to their offspring is limited. The "Lack clutch" is therefore defined as the clutch size which fledges the largest number of offspring. In the following years Lack's theory has been refined and the above mentioned trade-offs have been incorporated $[4,5]$. The most common approach to test the assumptions of the "Lack clutch" or to investigate optimality of clutch or litter size is to manipulate the number of offspring to assess whether this reduces or increases the reproductive success of the parents and the offspring. A variety of manipulative experiments have been conducted in birds, with contrasting results. For example, Styrsky et al. [6] found that brood size enlargement in spotted antbirds (Hylophylax naevioides) increases juvenile mortality after fledging, whereas brood size reductions resulted in the opposite effect. Other studies found a delay of egg-laying and a decrease in the number of successfully reared young in the next brood for rooks (Corvus frugilegus L.) with experimentally enlarged broods [7]. A meta-analysis on 42 brood size manipulation experiments, on the other hand, found no evidence for the Lack hypotheses. Brood size enlargement did not lead to a reduction in the number of fledglings [8]. Optimal litter size theory has also been 
applied to other vertebrates (mammals [9]; reptiles [10]) and invertebrates [11].

In mammals, litter size manipulations are usually conducted shortly after birth by adding or removing pups of similar age. Such manipulations affected the growth rate of offspring in rodents (white-footed mice (Peromyscus leucopus) [12], wild bank voles (Myodes glareolus) [13,14]) and the future reproductive success of females and their daughters (house mice (Mus musculus domestics) [15]). Other studies, in contrast, did not observe an effect of litter size manipulation on offspring condition (ground squirrels (Spermophilus columbianus) [16]) or female future reproduction (wild bank voles [13,14], ground squirrels [16]). Correlational data also suggests that there is no such trade-off (northern grasshopper mice (Onychomys leucogaster [17]). This discrepancy between different studies and methods (observational, versus experimental litter size manipulations) may indicate that postpartum manipulation of offspring number does not reflect a "naturally" large or small litter size. If females give birth to a litter size that is optimised to their current physiology and condition, manipulation of number of pups directly after birth will not result in standardization of lactational burden for different females (for a review see [18], and next section).

\section{Problems associated with experimental litter size manipulations}

One main problem of clutch or litter size manipulation experiments is that they do not account for the energy already invested into the production of the offspring. The cost of egg production and incubation in birds was largely ignored, until Monaghan et al. [19] showed that it can have a substantial effect and should not be overlooked. In altricial house mice, energy demand increases during gestation by $49.2 \%$ (compared to nonreproducing females [20]). Such an increase is substantial, although lactation comes at even higher costs (house mice [20], bank voles [21]).

Pregnancy in eutherian mammals further differs from the pre-incubating phase in egg-laying birds by its effect on the mother's hormones and behaviour. Mammary development begins already during gestation, and in utero litter size directly affects hormone levels (goats [22-24], mice [25]), mammary gland size (sheep [26], goats [22], mice [27]) and therefore likely also milk yield after birth (goats [23]). In addition, body weight of pregnant females increases with increasing prepartum litter size or litter mass [28]. Such an effect may have consequences for later lactation since heavier females produce more milk than smaller ones [29].

Despite the influence of in utero number of pups on maternal physiology and behaviour, adjustment to modified postpartum litter size is possible. Experimental litter size manipulation after birth revealed compensatory mammary growth in the first days of lactation, suggesting an ability to adjust milk production to changing litter sizes after birth [27-29]. Nevertheless, to what extent pre- and postpartum litter sizes influence maternal behaviour and lactation remains controversial. Analysing that question requires methods to manipulate litter size during gestation. One option is to surgically remove embryos at an early stage of the pregnancy (house mice [30]). This surgical method, however, is very invasive and the effects of the surgery difficult to control. Similar problems could arise after the removal of one of the ovaries prior to breeding. This method has been used in pigs to reduce litter size [31].

\section{The $t$ haplotype as a tool to manipulate litter size}

As an alternative, we propose here to use the $t$ haplotype as a genetic tool to reduce litter size in an eutherian mammal, the house mouse, which is widely used as a laboratory animal. This method allows for a predictable noninvasive litter size reduction without postnatal interference. The $t$ haplotype is a selfish genetic element occurring in natural house mouse populations (for a review see [32]). It is located on chromosome 17 and consists of four linked inversions, spanning approximately one third of the whole chromosome [32]. The $t$ haplotype has been described for all four subspecies of the house mouse (Mus m. domesticus, Mus m. musculus, Mus m. castaneus and Mus m. bactrianus) [32,33]. Gene products of the $t$ haplotype affect the development of the flagella of wild type sperm during spermatogenesis in $+/ t$ males, leading to a transmission ratio distortion with a $t$ gamete transmission of up to $99 \%$ to the offspring [32]. In females $t$ gamete transmission follows the classical Mendelian rule with on average $50 \%$ of the gametes receiving the $t$ haplotype. By amplifying and scoring a genetic marker (Hba-ps4) associated with the $t$ haplotype [33], this selfish genetic element can easily be identified. The $t$ can be found in many wild populations and several different $t$ variants are commercially available (to give an example: mouse strains $t^{w 5}$ (RBRC01202) and $t^{w 5 G}$ (RBRC01203) from the Experimental Animal Division of the RIKEN BioResource Center). Because of the transmission ratio distortion in males, the $t$ can be crossed into a population or specific strain within a rather short time (see [34]).

Most of the different $t$ variants carry recessive lethals, causing the death of homozygous individuals in utero. The stage in which lethality occurs varies between $t$ variants, but most often it happens around day 9 or 10 of pregnancy [35]. At this stage embryos are typically between $1.2 \mathrm{~mm}$ [day 9] and $3.9 \mathrm{~mm}$ [day 10] in size [36]. Nagasawa et al. [30] surgically adjusted the number of foetuses at day 8 of pregnancy in mice. They sacrificed the females at day 19 of pregnancy and analysed mammary 
development. The indices used to measure mammary development correlated positively with the number of embryos left after surgery suggesting that prepartum litter size (after day 8 of pregnancy) quantitatively influenced the development of the mammary gland tissue. The litter size reduction due to the recessive lethal nature of the $t$ haplotype, acting in the first half of the gestation period as described above, should therefore still allow for adjustment of prenatal mammogenesis to the number of surviving embryos. It is exactly the recessive lethal property of the $t$ haplotype that can be used as an instrument to reduce litter size, without interfering after birth, or applying invasive surgery to remove foetuses.

\section{Results and discussion}

Under standardised laboratory conditions, we analysed litter sizes at birth from four different mating crosses of $+/ t$ and $+/+$ house mice, originating from a wild population. A significant litter size reduction was observed when $+/ t$ females were mated with $+/ t$ males $\left(F_{3,123}=86.79\right.$, p-value $<0.001)$ [37]. Model estimates of the mean are displayed in Figure 1. The litter size at birth of $+/ t$ females mated with $+/ t$ males was approximately $40 \%$ smaller than the litter size of any other mating cross (figure one, [37]).

Like all methods, this genetic tool comes with some limitations. Manipulation is only possible in one direction. Litter size can only be reduced, but not increased. Increasing litter size requires another method. Currently, litter size can be increased prepartum by inducing superovulation with gonadotrophins (house mice [38], sheep [39], bank voles [40]).

Furthermore, based on the mating design required for reduced litter sizes at birth, females with small and standard litters will either differ in their genotype $(+/ t$ or $+/+)$ or the genotype $(+/ t$ or $+/+)$ of the sire of their litter, or both. It is therefore not possible to completely disentangle other effects of the $t$ besides the reduction in litter size. The $t$ is known to affect functional sperm in males and behavioural studies have revealed that $+/ t$ females prefer $+/+$ males over $+/ t$ males, probably to avoid a reduction in litter size $[37,41]$. In the population from which our experimental animals derived, the $t$ is associated with a unique MHC haplotype, and could thus play a role in $t$ dependent mate choice [37]. Nevertheless, we

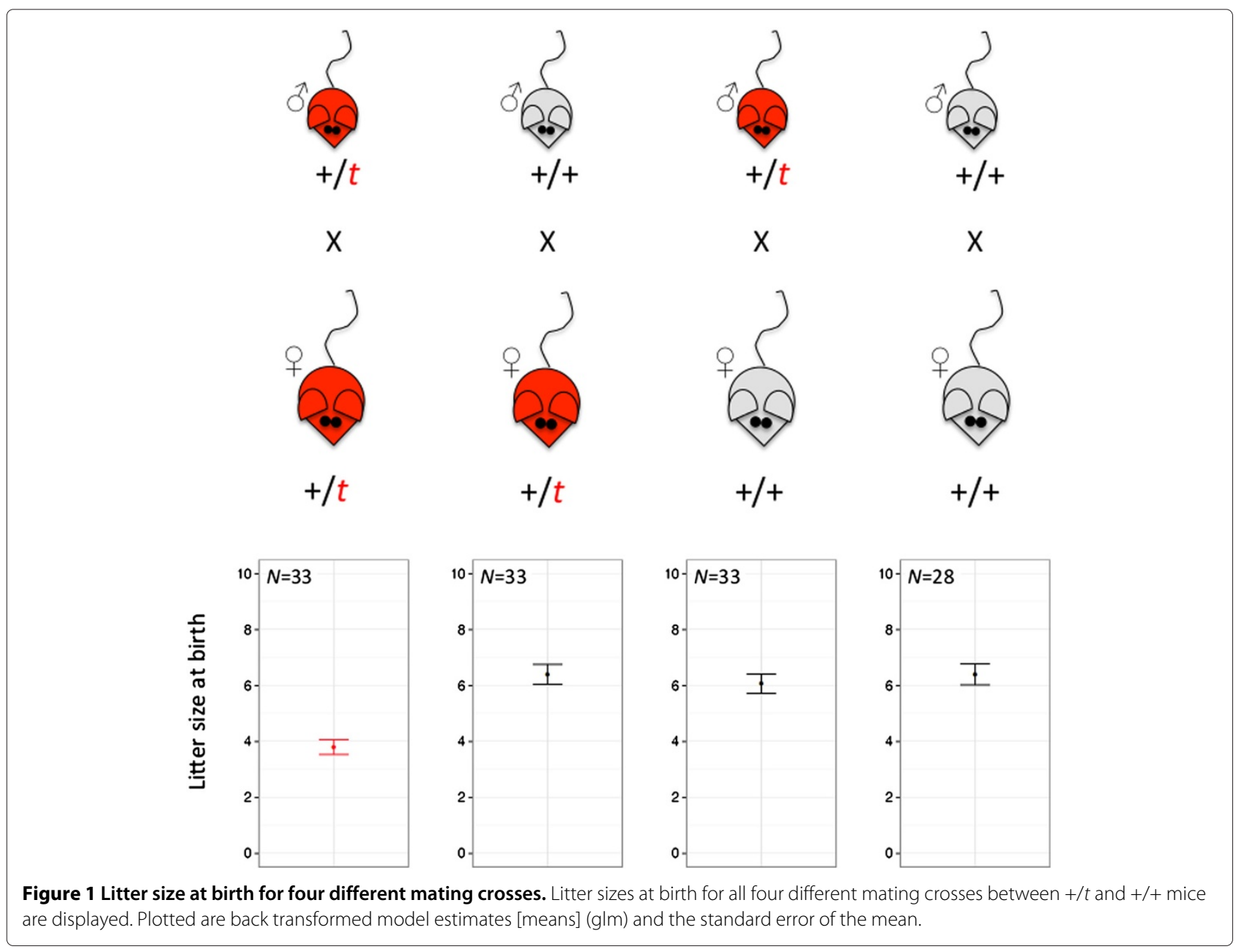


do not expect mate choice to be a confounding factor in the setting presented here. First, litter size manipulation experiments are typically conducted in the laboratory and females are paired monogamously with males. In our laboratory crossings, both $+/+$ and $+/ t$ females did not differ in their propensity to conceive and to give birth when mated with $+/ t$ compared to $+/+$ males [37], indicating that they did not discriminate against $+/ t$ males. Second, the majority of experiments using litter size manipulations in house mice focus on the behaviour of the dams and/or the offspring, and there are up to now no indications that the $t$ directly influences maternal behaviour.

A rather simple experimental design could thus help to answer to what extent prepartum versus postpartum number of offspring influences female reproductive costs, physiology and behaviour, by combining the genetic method to manipulate litter size prenatally with manipulations of litter size at birth. Furthermore, $+/ t$ females can alternatively be paired with $a+/ t$ male and with $a+/+$ male (full-sibs if required), or vice versa, therefore making it possible to compare data from the same female, once with a reduced and then with a standard litter size. In addition litter size reductions could help to reduce the number of mice born during experiments (in line with the $3 \mathrm{R}$ recommendations [42]).

\section{Conclusions}

Experimental litter or clutch size manipulations are an important tool for gaining insight into the optimal litter size, and ultimately to understand life history strategies. Such manipulations can however cause substantial problems whenever the energy invested into the production of eggs or into gestation is ignored. Using a recessive lethal gene can help to reduce litters or clutches in a predictive way without interference after birth or oviposition. Recessive lethals can only generate litters that are reduced on average by $25 \%$, but the transmission ratio distortion caused by the $t$ haplotype in male house mice results in a litter size reduction of up to $50 \%$. The earlier the recessive lethal property of the gene works, the better it controls for the prenatal costs of reproduction and potential prenatal adjustments to the litter size. Selfish genetic elements are assumed to be wide spread and often associated with recessive lethals, therefore similar methods could apply for a whole array of species [43]. This novel method allows the generation of smaller litters in a mammalian species without interfering after birth or using invasive techniques.

\section{Materials and methods}

The data presented in this study were collected as part of a larger data set [37]. Data from experiment 1 and 2 of [37] were pooled for this analysis. In short, mice used were F1 to F3 descendants from wild house mice caught between
2006 and 2008 at a study population in Illnau, near Zurich, Switzerland. For more details on the free living study population see $[37,44]$. Experiments were conducted in an animal facility at the University of Zurich. Animal experimentation was approved by the Swiss Animal Experimentation Commission (Kantonale Tierversuchskommission, licence no. 97/2009). Prior to the experiments mice were kept in same-sex sibling groups after they had been removed from their parental cage at an age of 28 days. At that point a tissue sample was taken from each mouse for genotyping. The $t$ haplotype was identified by scoring the genotype at the $\mathrm{Hba-ps} 4$ locus [33] (for a detailed method see [37]). Mice used in the experiment inherited the $t$ from the paternal, or maternal side. For simplicity, we always refer with $+/ t$ to heterozygous individuals, irrespective of whether they inherited the $t$ from their mother or father. To our knowledge there are no imprinting effects known for the $t$ haplotype.

During the experiments a male and a virgin female were kept together in a Macrolon type III cage $(425 \mathrm{~mm} \times$ $266 \mathrm{~mm} \times 155 \mathrm{~mm}$ ). The male was removed from the cage after 14 days and from day 19 onwards, cages were checked daily for new litters. After birth cages were searched for living and dead pups. All possible combinations of crosses between $+/ t$ and $+/+$ mice were used. In total 127 mating crosses were analysed. The exact numbers of each combination are indicated in Figure 1.

\section{Statistical analysis}

All analyses were performed with R 2.15.1 [45]. A generalised linear model (glm) was used to test for an effect of the four different mating crosses on the litter size. The glm was fitted using a quasipoisson error distribution with a log-link function. Significance was tested by conducting F-tests, alpha was taken to be 0.05 .

\section{Competing interests}

The authors declare that they have no competing interests.

\section{Authors' contributions}

MF confirmed the method in yet unpublished work and wrote the main text. $\mathrm{AL}$ conceived the methodological idea, performed the mating crosses and contributed to the text. BK supervised the work and contributed to the text. All authors read and approved the final manuscript.

\section{Acknowledgements}

We thank Jari Garbely for laboratory work and Gabriele Stichel for taking care of the breeding colony. Yannick Auclair, Andreas Sutter and Patricia Lopes kindly commented on the manuscript. This study was funded by SNSF grant $3100 \mathrm{AO}-120444$.

Received: 4 July 2013 Accepted: 17 February 2014

Published: 24 February 2014

References

1. Pianka ER: Natural selection of optimal reproductive tactics. Am Zool 1976, 16(4):775-784

2. Godfray HCJ, Partridge L, Harvey PH: Clutch size. Ann Rev Ecol Systematics 1991, 22(1):409-429.

3. Lack D: The significance of clutch-size. Ibis 1947, 89(2):302-352 
4. Williams GC: Natural selection, the costs of reproduction, and a refinement of lack's principle. Am Nat 1966, 100(916):687-690.

5. Stearns SC: The evolution of life histories. Oxford: Oxford University Press; 1992

6. Styrsky JN, Brawn JD, Robinson SK: Juvenile mortality increases with clutch size in a neotropical bird. Ecology 2005, 86(12):3238-3244.

7. Roskaft $E$ : The effect of enlarged brood size on the future reproductive potential of the rook. J Anim Ecol 1985, 54(1):255-260.

8. Werf EV: Lack's clutch size hypothesis: an examination of the evidence using meta-analysis. Ecology 1992, 73(5):1699-1705.

9. Sikes $\mathrm{RS}$, $\mathrm{Ylönen} \mathrm{H}$ : Considerations of optimal litter size in mammals. Oikos 1998, 83(3):452-465

10. Aubret F, Bonnet $X$, Shine $R$, Maumelat S: Clutch size manipulation, hatching success and offspring phenotype in the ball python (Python regius). Biol J Linnean Soc 2003, 78(2):263-272.

11. Hardy ICW, Griffiths NT, Godfray HCJ: Clutch size in a parasitoid wasp: a manipulation experiment. J Anim Ecol 1992, 61(1):121-129.

12. Fleming TH, Rauscher RJ: On the evolution of litter size in Peromyscus leucopus. Evolution 1978, 32(1):45-55.

13. Koskela E: Offspring growth, survival and reproductive success in the bank vole: a litter size manipulation experiment. Oecologia 1998, 115(3):379-384

14. Mappes T, Koskela $\mathrm{E}$, Ylonen $\mathrm{H}$ : Reproductive costs and litter size in the bank vole. Proc R Soc London. Series B: Biol Sci 1995, 261(1360):19-24.

15. Fuchs S: Optimality of parental investment: the influence of nursing on reproductive success of mother and female young house mice. Behav Ecol Sociobiol 1982, 10(1):39-51.

16. Hare JF, Murie JO: Manipulation of litter size reveals no cost of reproduction in columbian ground squirrels. J Mammal 1992, 73(2):449-454.

17. Sikes RS: Tradeoffs between quality of offspring and litter size: differences do not persist into adulthood. J Mammal 1998, 79(4):1143-1151.

18. Jameson EWJ: Prepartum mammogenesis, milk production, and optimal litter size. Oecologia 1998, 114(2):288-291.

19. Monaghan $P$, Nager RG, Houston DC: The price of eggs: increased investment in egg production reduces the offspring rearing capacity of parents. Proc R Soc London. Series B: Biol SCi 1998, 265(1407) 1731-1735

20. Speakman JR, McQueenie J: Limits to sustained metabolic rate: the link between food intake, basal metabolic rate, and morphology in reproducing mice, Mus musculus. Physiol Zool 1996, 69(4): 746-769.

21. Migula P: Bioenergetics of pregnancy and lactation in european common vole. Acta Theriol 1969, 14(13):167-179.

22. Hayden TJ, Thomas CR, Smith SV, Forsyth IA: Placental lactogen in the goat in relation to stage of gestation, number of fetuses, metabolites, progesterone and the time of day. J Endocrinol 1980, 86(2):279-290.

23. Hayden TJ, Thomas CR, Forsyth IA: Effect of number of young born (litter size) on milk yield of goats role for placental lactogen. J Dairy Sci 1979, 62(1):53-57.

24. Manalu W, Sumaryadi MY, Kusumorini N: Effect of fetal number on the concentrations of circulating maternal serum progesterone and estradiol of does during late pregnancy. Small Ruminant Res 1997, 23(2-3):117-124.

25. Soares M, Talamantes F: Genetic and litter size effects on serum placental lactogen in the mouse. Biol Reprod 1983, 29(1):165-171.

26. Rattray PV, Garrett WN, East NE, Hinman N: Growth, development and composition of the ovine conceptus and mammary gland during pregnancy. J Anim Sci 1974, 38(3):613-626.

27. Knight $\mathrm{CH}$ : Mammary development in mice: effects of hemihysterectomy in pregnancy and of litter size post partum. J Physiol 1982, 327(1):17

28. Duah OA, Monney KA, Hambly C, Król E, Speakman JR: Limits to sustained energy intake. xvii. lactation performance in $\mathrm{mf} 1 \mathrm{mice}$ is not programmed by fetal number during pregnancy. J Exp Bio/ 2013 216(12):2339-2348

29. König B, Riester J, Markl H: Maternal care in house mice (Mus musculus): li. the energy cost of lactation as a function of litter size. J Zool 1988, 216(2):195-210.
30. Nagasawa $H$, Yanai R: Quantitative participation of placental mammotropic hormones in mammary development during pregnancy of mice. Endocrinol Jpn 1971, 18(6):507-510.

31. Kensinger RS, Collier RJ, Bazer FW: Effect of number of conceptuses on maternal mammary development during pregnancy in the pig. Domest Anim Endocrinol 1986, 3(4):237-245.

32. Silver $L M$ : The peculiar journey of a selfish chromosome: mouse $\mathbf{t}$ haplotypes and meiotic drive. Trends Genet 1993, 9(7):250-254.

33. Hammer MF, Schimenti J, Silver LM: Evolution of mouse chromosome 17 and the origin of inversions associated with thaplotypes. Proc Nat Acad Sci 1989, 86(9):3261-3265.

34. Lenington $S$, Coopersmith CB, Erhart M: Female preference and variability among t-haplotypes in wild house mice. Am Nat 1994, 143(5):766-784

35. Safronova LD: Embryonal effects of t-haplotypes in mice. Russ J Dev Biol 2009, 40(1):23-30

36. Theiler K: The house mouse: Atlas of embryonic development. New York: Springer-Verlag; 1989

37. Lindholm AK, Musolf K, Weidt A, König B: Mate choice for genetic compatibility in the house mouse. Ecol Evol 2013, 3(5):1231-1247.

38. Wilson ED, Edwards R: Parturition and increased litter size in mice after superovulation. J Reprod Fertil 1963, 5(2):179-186.

39. Newton JE, Betts JE, Large RV: Increasing litter size in three breeds of sheep by superovulation. J Agric Sci 1970, 75(2):355-360.

40. Oksanen TA, Koskela E, Mappes T: Hormonal manipulation of offspring number: maternal effort and reproductive costs. Evolution 2002 56(7):1530-1537

41. Lenington S, Coopersmith C, Williams J: Genetic basis of mating preferences in wild house mice. Am Zool 1992, 32(1):40-47.

42. Russell WMS, Burch RL, Hume CW: The principles of humane experimental technique. London: Methuen; 1959

43. Burt A, Trivers RL: Genes in conflict: The biology of selfish genetic elements. Harvard: Belknap Press; 2006

44. König B, Lindholm A: The complex social environment of female house mice (Mus domesticus). In Evolution of the House Mouse. Edited by Macholàn M, Baird SJE, Mundlinger P, Piàlek J. Cambridge: Cambridge University Press; 2012:114-134.

45. R Core Team: R: A Language and Environment for Statistical Computing. 2012. [http://www.R-project.org/]

doi:10.1186/1742-9994-11-18

Cite this article as: Ferrari et al.: A genetic tool to manipulate litter size. Frontiers in Zoology 2014 11:18.

Submit your next manuscript to BioMed Central and take full advantage of:

- Convenient online submission

- Thorough peer review

- No space constraints or color figure charges

- Immediate publication on acceptance

- Inclusion in PubMed, CAS, Scopus and Google Scholar

- Research which is freely available for redistribution 